\title{
Reduction in Prevalence of Hypertension and Blood Heavy Metals among Curry-Consumed Korean
}

\author{
Jo-Woong Choi, ${ }^{1, *}$ Chorong Oh, ${ }^{2, *}$ Sun-Yup Shim, ${ }^{1,3, *}$ Suyoun Jeong, ${ }^{4}$ \\ Hyung Sik Kim ${ }^{5}$ and Min-Sun Kim ${ }^{1,3}$

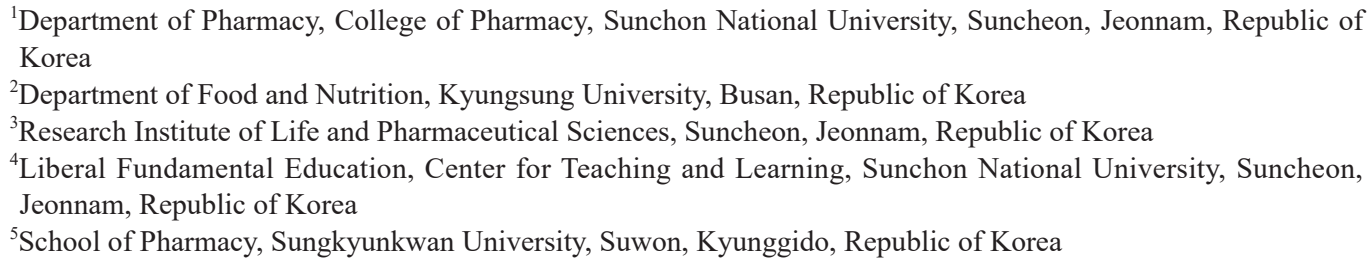

Curcuma longa is rich in curcumin and used to treat disease and in food as a spice, especially in curry dishes. The objective of the present study was to determine whether curry intake reduces blood levels of heavy metals and hypertension (HTN) using Korean National Health and Nutrition Examination Survey 2013 data $(n=1,350)$. Study subjects $(n=1,350)$ were divided into two groups: 1$)$ a curry intake group $(n$ $=603$ ), members of which had consumed a curry dish more than once a month over the previous year, and 2 ) a non-curry intake group $(n=747)$. Analysis showed the curry intake group had significantly lower heavy metal blood concentrations $(\mathrm{Pb}, \mathrm{Hg}$, and $\mathrm{Cd}$ ) and blood concentrations of heavy metals were significantly associated with prevalence of $\mathrm{HTN}(P<0.001 \mathrm{for} \mathrm{Pb}, \mathrm{Hg}$, and $\mathrm{Cd})$. Curry intake also reduced the risk of HTN prevalence (odd ratios for curry intake vs. non-curry intake; $\mathrm{Pb}, 1.503$ vs. $1.862 ; \mathrm{Hg}, 1.112$ vs. 1.149; $\mathrm{Cd}, 1.676$ vs. 1.988). Logistic regression analysis was used to confirm the association between blood heavy metal levels and HTN. After adjusting for age, sex, lifetime smoking, and body mass index, the odd ratio of HTN was significant in the non-curry intake group, but not in the curry intake group, implying other factors influenced relations in the curry intake group. In view of the importance of curry consumption with reduced concentrations of heavy metals in blood and the prevalence of HTN, we suggest further welldesigned clinical trials be conducted.

Keywords: blood concentrations of heavy metals; curry intake; hypertension; Korea National Health and Nutrition Examination Survey; logistic regression

Tohoku J. Exp. Med., 2018 March, 244 (3), 219-229. $\quad$ (C) 2018 Tohoku University Medical Press

\section{Introduction}

Root of Curcuma longa Linn (a member of the ginger family), named "curry", is used as a spice in many Asian countries, including India and Thailand (Kwon 2014). Curcumin [1,7-bis(4-hydroxy-3-methoxyphenyl)-1,6heptadien-3,5-dione] is a major component of curry, and has various physiological activities, including anti-inflammatory, anti-oxidative, and anti-tumor activities (Cao et al. 2017; Zhou et al. 2017). Higher concentrations of curcumin (1.5-6 g/day) are effective in cancer treatment (Kuriakose et al. 2016; Mahammedi et al. 2016). Reports indicate curcumin can improve cognitive function and cardiovascular health (Kukongviriyapan et al. 2016; Wu et al. 2017). Curcumin can also act as a chelating agent for heavy metal ions, thus lowering their concentrations in blood (Kukongviriyapan et al. 2016). In addition, curcumin has been used traditionally to relieve or treat other diseases and has been extensively studied because of its physiological activities (Sinha et al. 2003).

Exposure to heavy metals, such as lead $(\mathrm{Pb})$, mercury $(\mathrm{Hg})$, and cadmium $(\mathrm{Cd})$, emitted by automobiles and factories or in contaminated seafood is a major environmental concern (Kim et al. 2015). Heavy metals accumulate in kidney cortex, bones, and lungs. Half-lives in vivo are several decades, and thus, their burden will increase in the body (Pal et al. 2015). Environmental sources of $\mathrm{Pb}$ include contaminated food, air, soil, and water. Hg exposure sources include contaminated waste, air, and food, especially contaminated fish and seafood (Camur et al.

Received October 10, 2017; revised and accepted February 23, 2018. Published online March 20, 2018; doi: 10.1620/tjem.244.219.

*These three authors contributed equally to this work.

Correspondence: Min-Sun Kim, Department of Pharmacy, College of Pharmacy, Sunchon National University, 255 Jungangro, Suncheon, Jeonnam 57922, Republic of Korea.

e-mail: minsun@sunchon.ac.kr 
2016). In fact, people that consume seafood at least once a week exhibit significantly higher $\mathrm{Hg}$ levels in blood (Lincoln et al. 2011). Cd exposure sources mainly include cigarette smoking and contaminated food (Satarug et al. 2017a). Exposure to heavy metals has many risk factors, which include age, sex, smoking, body mass index (BMI), and others (Kim et al. 2017). Because heavy metals accumulate in vivo, as we age, their blood concentrations increase. For $\mathrm{Pb}$, highest accumulation occurs in bones and increases with age (Nascimento et al. 2016). Interestingly, the absorptions of heavy metals depend on sex. In premenopausal females, elevated $\mathrm{Cd}$ in blood is associated with iron (Fe) deficiency (Lee and Kim 2014). Smoking is also another risk factor of heavy metal exposure (Dai et al. 2015).

Heavy metals in blood are related to various diseases, including hypertension (HTN) and diabetes. $\mathrm{Pb}$ and $\mathrm{Cd}$ can perturb blood coagulation and increase the risk of cardiovascular disease (CVD) (Arbi et al. 2017). HTN, a common chronic disease, is a risk factor of CVD (RodriguezIturbe et al. 2017) and is defined as a systolic blood pressure $>140 \mathrm{mmHg}$ or a diastolic blood pressure of $>90 \mathrm{mmHg}$ in adults over 18 years of age. Causes of HTN include environmental and psychological factors, such as family history, drinking alcohol, smoking, age, lack of exercise, obesity, eating habits, and stress (Liu et al. 2017). Furthermore, heavy metal exposure has been reported to be positively associated with HTN (An et al. 2017). Rats intramuscularly injected with $\mathrm{Pb}$ acetate for 30 days (first dose $4 \mu \mathrm{g} / 100 \mathrm{~g}$ followed by $0.05 \mu \mathrm{g} / 100 \mathrm{~g} /$ day, i.m.) exhibited systolic blood, mean arterial, and diastolic blood pressure increases (Simoes et al. 2017). On the other hand, $\mathrm{Cd}$ catalyzes the production of reactive oxygen species
(ROS), and thus, can damage vascular endothelial cells, and induce the release of inflammatory mediators and antithrombotic substances that exacerbate HTN (Yamamoto et al. 1993; Angeli et al. 2013).

The adoption of Western dietary patterns by Koreans has resulted in increases in the incidences of chronic diseases like obesity and related cardiovascular diseases (Astrup et al. 2008), and it has been shown HTN is more likely to occur in those who consume westernized food than in those who consume traditional Korean foods (Kim 2009; Shin et al. 2013). High kidney Cd concentrations have been associated with the prevalence of diabetes or HTN (Satarug et al. 2017a) and an association between obesity with heavy metal levels in blood has been reported (Sun et al. 2017). It has also been reported even low-level exposure to $\mathrm{Cd}$ might increase the risk of bone fracture (Wallin et al. 2016) and metabolic syndrome (Go et al. 2015).

The objective of the present study was to determine whether regular curry consumption reduces the blood levels of heavy metals and the prevalence of HTN using the Korea National Health and Nutritional Examination Survey (KNHANES) 2013 data.

\section{Materials and Methods}

Study subjects

KNHANES is a cross-sectional study composed of three components: a health interview, a health examination, and a nutrition survey. KNHANES 2013 data were used in the present study. A flow diagram describing the study subject selection process is provided in Fig. 1. We excluded participants that did not provide the following information: curry intake ( $n=4,237)$, heavy metal concentration in blood ( $n=2,339)$, presence of HTN or diabetes, body mass index (BMI), lifetime smoking, or level of education $(n=78)$. Pregnant

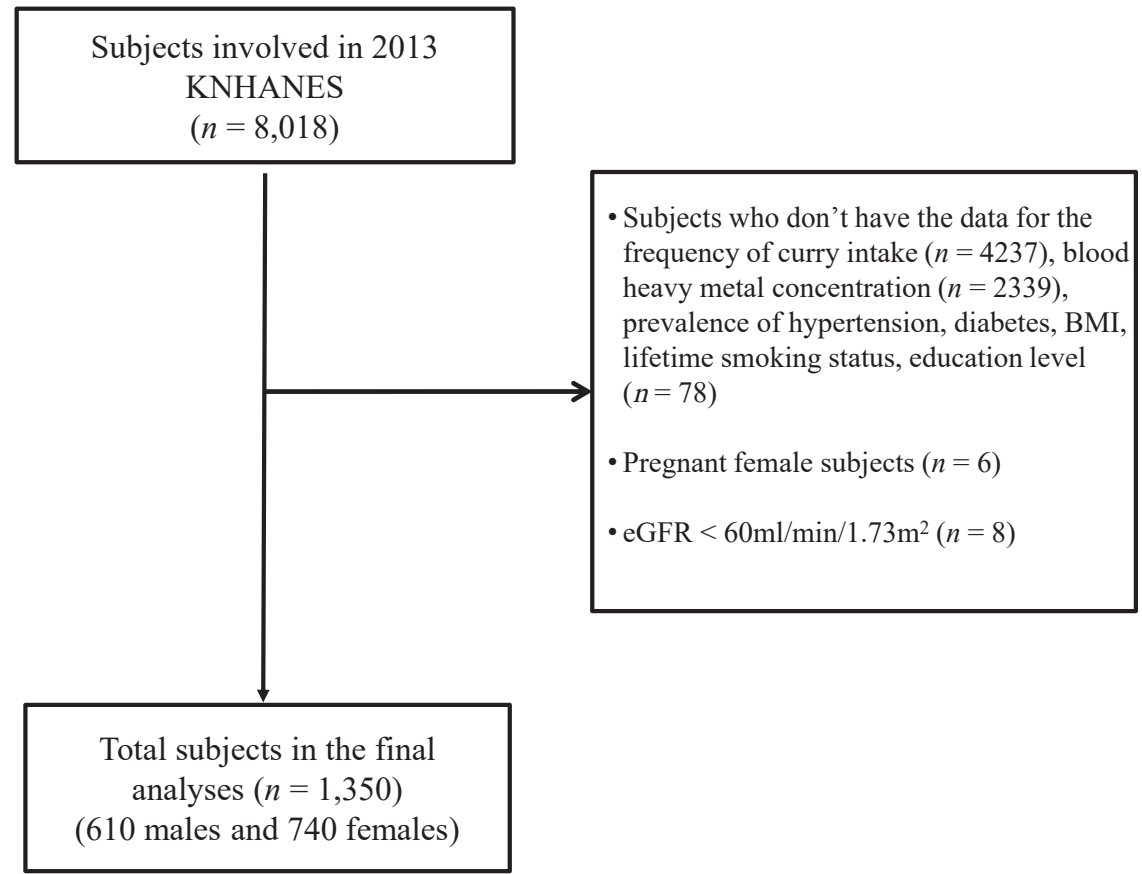

Fig. 1. Flow diagram of study subject selection process. 
women $(n=6)$ and those with an estimated glomerular filtration rate (eGFR) of less than $60 \mathrm{~mL} / \mathrm{min} / 1.73 \mathrm{~m}^{2}(n=8)$ also were excluded. eGFR values were used as indicators of glomerular function and calculated using a Modification of Diet in Renal Disease (MDRD) study equation (Schwandt et al. 2017). GFR $\left(\mathrm{ml} / \mathrm{min} / 1.73 \mathrm{~m}^{2}\right)_{\text {MDRD }}=186 \times$ $[\operatorname{Scr}(\mathrm{mg} / \mathrm{dL})]^{-1.154} \times[\text { age (years) }]^{-0.203}(\times 0.742$ if female $)$. Serum creatinine values used in the eGFR calculation were measured using a kinetic Jaffe method and an autoanalyzer (model 7600; Hitachi, Tokyo, Japan). Because HTN can be associated with kidney failure and heavy metals are excreted in proximal kidney tubules and affect glomerular filtration rate (Kim and Lee 2012), we excluded those with a eGFR of less than $60 \mathrm{~mL} / \mathrm{min} / 1.73 \mathrm{~m}^{2}$. Of the 8,108 participants in KNHANES, we finally selected 1,350 subjects (610 males and 740 females) for the present study. Of these, 747 subjects (55.3\%) had hardly consumed curry and 603 subjects (44.7\%) consumed curry at least once a month.

\section{Parameters}

Basal parameters used in this study were sex, age, residence, education level, smoking status, presence of HTN or diabetes mellitus, BMI, and blood heavy metal concentrations. Locations of residence were classified as urban or rural. Education levels were classified as college level or over or less than college level. Lifetime smoking and current diabetes were classified as yes or no. Subjects who had never smoked during their lifetime were classified as nonsmokers while those with a smoking history (ex-smokers) or were smoking currently (current smokers) were classified as lifetime smokers. HTN was classified as no HTN, pre-HTN, or HTN. HTN was defined as a systolic blood pressure $>140 \mathrm{mmHg}$, a diastolic blood pressure $>90 \mathrm{mmHg}$, or currently taking a HTN drug. Pre-HTN phase was defined as a systolic blood pressure of $>120 \mathrm{mmHg}$ but $<140 \mathrm{mmHg}$ and a diastolic blood pressure $>80 \mathrm{mmHg}$ but $<90$ $\mathrm{mmHg}$ in the absence of a HTN drug. Subjects with a systolic blood pressure of $<120 \mathrm{mmHg}$ and a diastolic blood pressure of $<80$ $\mathrm{mmHg}$ not taking high blood pressure medication were defined as not having HTN. For convenience, subjects without HTN or with preHTN were assigned to a normal HTN group for logistic regression analysis.

\section{Determination of $\mathrm{Pb}, \mathrm{Hg}$, and $\mathrm{Cd}$ in blood}

Blood sampling and $\mathrm{Pb}, \mathrm{Hg}$, and $\mathrm{Cd}$ analyses were performed by the Neodin Medical Institute, which is certified by the Korean Ministry of Labor for the analysis of heavy metals, and meets the requirements of the German External Quality Assessment Scheme, the U.S. CDC program, and the Korea Occupational Safety and Health Administration (Korea OSHA) program (KCDC, Korea Centers for Disease Control and Prevention 2013). $\mathrm{Pb}$ and $\mathrm{Cd}$ were measured by graphite furnace atomic absorption spectrometry (model AAnalyst 600; Perkin Elmer, Turku, Finland) using the Zeeman background correction, and total $\mathrm{Hg}$ was measured using a direct mercury analyzer (model DMA-80 Analyzer; Bergamo, Italy) and the gold amalgam method (KCDC 2013). Limits of detection (LODs) were $0.223 \mu \mathrm{g} / \mathrm{dL}, 0.05 \mu \mathrm{g} / \mathrm{L}, 0.087 \mu \mathrm{g} / \mathrm{L}$ for $\mathrm{Pb}, \mathrm{Hg}$, and $\mathrm{Cd}$, respectively. No adult sample had a value of below a LOD, and only 4 adolescent samples had Cd values $(0.043,0.064,0.067,0.078)$ below its LOD. For internal quality assurance and control, commercial standard reference materials were purchased from Bio-Rad (Lyphocheck Whole Blood Metals Control; Bio-Rad, Hercules, CA, USA).

\section{Statistical analysis}

A complex sampling design was used in the study. All statistical analyses were conducted using SPSS version 24.0 (SPSS, IBM, NY, USA). Chi-squared tests were used to investigate relations between curry intake and demographic factors, such as, sex, age, and residence. A generalized linear model was used to investigate mean concentrations of heavy metals and curry intake. Logistic regression analysis was used to calculate odd ratios (ORs) with $95 \%$ confidence intervals (CIs) for the effects of heavy metals on the prevalence of HTN after adjusting for age, sex, smoking status, and BMI. Statistical significance was accepted for two-tailed $p$ value of $<0.05$.

\section{Ethics statement}

KNHANES 2013 was approved by the Research Ethics Review Board of the KCDC (IRB No. 2013-07CON-03-4C). All participants in KNHANES provided written informed consent before examinations, which were performed by the Health and Nutrition Examination Department of the KCDC.

\section{Results}

\section{Characteristics of subjects}

Basic characteristics of subjects such as sex, age, BMI, residence, educational level, lifetime smoking, diabetes, and heavy metal concentrations in blood are summarized in Table 1. The study comprised of 610 males $(45.2 \%)$ and 740 females (54.8\%) aged from 19 to 64 years. The 1,350 study subjects were divided into five groups: 19-29 years (20s), 23.1\% $(n=312)$; 30-39 years $(30 \mathrm{~s}), 22.7 \%(n=307)$; $40-49$ years $(40 \mathrm{~s}), 21.9 \%(n=296) ; 50-59$ years $(50 \mathrm{~s})$, $22.1 \%(n=298)$; and $60-64$ years $(60 \mathrm{~s}), 10.1 \%(n=137))$. Overall average BMI was $23.60 \pm 0.097 \mathrm{~kg} / \mathrm{m}^{2}$. Subject residences, for $83.5 \%(n=1,127)$ were urban and rural for $16.5 \%(n=223)$. Regarding educational level, $51.4 \%(n=$ 694) were educated to at least the college level and $48.6 \%$ $(n=656)$ were not. Lifetime smoking was divided into smokers $39.3 \%(n=531)$ and non-smokers $60.7 \%(n=$ 819). Ninety-four subjects $(7.0 \%)$ were assigned into the diabetics group and 1,256 subjects $(93.0 \%)$ to the nondiabetics group. For all study subjects, average blood concentrations of heavy metals were: $\mathrm{Pb}, 2.01 \pm 0.025 \mu \mathrm{g} /$ $\mathrm{dL} ; \mathrm{Hg}, 3.86 \pm 0.077 \mu \mathrm{g} / \mathrm{L}$; and $\mathrm{Cd}, 0.97 \pm 0.019 \mu \mathrm{g} / \mathrm{L}$.

Table 2 shows relations between demographic characteristics and heavy metal concentrations with respect to curry intake. No significant association was observed between sex or residence and curry intake. However, curry intake differed with respect to age $(P<0.001)$, and those in their $20 \mathrm{~s}, 30 \mathrm{~s}$ and $40 \mathrm{~s}$ ate curry more frequently. Blood concentrations of $\mathrm{Pb}, \mathrm{Hg}$, and $\mathrm{Cd}$ were significantly lower in curry intake group (curry intake vs. non-curry intake: $\mathrm{Pb}$ $(\mu \mathrm{g} / \mathrm{dL}), 1.97 \pm 0.043$ vs. $2.09 \pm 0.045, P=0.029 ; \mathrm{Hg}(\mu \mathrm{g} /$ L), $3.68 \pm 0.122$ vs. $4.05 \pm 0.125, P=0.017 ; \mathrm{Cd}(\mu \mathrm{g} / \mathrm{L})$, $0.86 \pm 0.023$ vs. $1.07 \pm 0.032, P<0.001$ ). In Table 3 , we analyzed data by dividing frequency of curry intake per month $(<$ once a month, once in a month, or $\geq$ twice a month). Heavy metal concentrations decreased significantly on increasing curry intake frequency ( $<$ once vs. once vs. $\geq$ twice: $\mathrm{Pb}(\mu \mathrm{g} / \mathrm{dL}), 2.097 \pm 0.045$ vs. $2.05 \pm 0.059$ 
J.W. Choi et al.

Table 1. Characteristics of 1,350 subjects in KNHANES.

\begin{tabular}{|c|c|c|c|}
\hline Variables & Group & $\begin{array}{l}\text { Total person } \\
(n=1350)\end{array}$ & $\mathrm{SE}$ \\
\hline \multirow[t]{2}{*}{ Sex } & Male & $610(45.2 \%)$ & \\
\hline & Female & $740(54.8 \%)$ & \\
\hline \multirow[t]{5}{*}{ Age (years) } & $19-29$ & $312(23.1 \%)$ & \\
\hline & $30-39$ & $307(22.7 \%)$ & \\
\hline & $40-49$ & $296(21.9 \%)$ & \\
\hline & $50-59$ & $298(22.1 \%)$ & \\
\hline & $60-64$ & $137(10.1 \%)$ & \\
\hline BMI $\left(\mathrm{kg} / \mathrm{m}^{2}\right)$ & & 23.60 & 0.097 \\
\hline \multirow[t]{2}{*}{ Residence } & Urban & $1,127(83.5 \%)$ & \\
\hline & Rural & $223(16.5 \%)$ & \\
\hline \multirow[t]{2}{*}{ Educational level } & Over college & $694(51.4 \%)$ & \\
\hline & Less than college & $656(48.6 \%)$ & \\
\hline \multirow[t]{2}{*}{ Lifetime smoking } & Smokers & $531(39.3 \%)$ & \\
\hline & Non-smokers & $819(60.7 \%)$ & \\
\hline \multirow[t]{2}{*}{ Diabetes } & Yes & $94(7.0 \%)$ & \\
\hline & No & $1256(93.0 \%)$ & \\
\hline Blood $\mathrm{Pb}$ concentration $(\mu \mathrm{g} / \mathrm{dL})$ & & 2.01 & 0.025 \\
\hline Blood $\mathrm{Hg}$ concentration $(\mu \mathrm{g} / \mathrm{L})$ & & 3.86 & 0.077 \\
\hline Blood Cd concentration $(\mu \mathrm{g} / \mathrm{L})^{\prime}$ & & 0.97 & 0.019 \\
\hline
\end{tabular}

Lifetime smokers were defined as current or ex-smokers, and nonsmokers were defined as those that had never smoked.

Table 2. Comparison of demographic characteristics and heavy metal blood concentrations in subjects the curry intake and non-curry intake groups.

\begin{tabular}{|c|c|c|c|c|c|c|}
\hline \multirow{2}{*}{ Variables } & \multirow[b]{2}{*}{ Group } & \multicolumn{4}{|c|}{ Curry intake } & \multirow[b]{2}{*}{$P$ value } \\
\hline & & \multicolumn{2}{|c|}{ Yes $(n=603) \mathrm{SE}$} & \multicolumn{2}{|c|}{ No $(n=747) \mathrm{SE}$} & \\
\hline \multirow[t]{2}{*}{ Sex } & Male & $45.8 \%$ & & $54.2 \%$ & & $0.283^{\mathrm{a}}$ \\
\hline & Female & $42.4 \%$ & & $57.6 \%$ & & \\
\hline \multirow[t]{5}{*}{ Age (years) } & $19-29$ & $50.1 \%$ & & $49.9 \%$ & & $<0.001^{* * *}$ \\
\hline & $30-39$ & $56.0 \%$ & & $44.0 \%$ & & \\
\hline & $40-49$ & $44.4 \%$ & & $55.6 \%$ & & \\
\hline & $50-59$ & $35.6 \%$ & & $64.4 \%$ & & \\
\hline & $60-64$ & $23.7 \%$ & & $76.3 \%$ & & \\
\hline \multirow[t]{2}{*}{ Residence } & Urban & $45.0 \%$ & & $55.0 \%$ & & 0.217 \\
\hline & Rural & $39.3 \%$ & & $60.7 \%$ & & \\
\hline \multicolumn{2}{|c|}{ Blood $\mathrm{Pb}$ concentration $(\mu \mathrm{g} / \mathrm{dL})^{\mathrm{b}}$} & 1.97 & 0.043 & 2.09 & 0.045 & $0.029^{*}, \mathrm{c}$ \\
\hline \multicolumn{2}{|c|}{ Blood $\mathrm{Hg}$ concentration $(\mu \mathrm{g} / \mathrm{L})^{\mathrm{b}}$} & 3.68 & 0.122 & 4.05 & 0.125 & $0.017^{*}$ \\
\hline \multicolumn{2}{|c|}{ Blood Cd concentration $(\mu \mathrm{g} / \mathrm{L})^{\mathrm{b}}$} & 0.86 & 0.023 & 1.07 & 0.032 & $<0.001^{* * *}$ \\
\hline
\end{tabular}

${ }^{a} P$ values were determined using chi-square test for categorical variables.

${ }^{b}$ Results are expressed as means \pm SEs.

${ }^{\mathrm{c}} \mathrm{Age}$, blood $\mathrm{Pb}, \mathrm{Hg}$, and $\mathrm{Cd}$ concentrations were treated as continuous variables.

$P$ values were calculated using a generalized linear model for continuous variables.

${ }^{*} P<0.05,{ }^{* *} P<0.01,{ }^{* * *} P<0.001$. 
Table 3. Curry intake frequency per month and heavy metal blood concentrations.

\begin{tabular}{lllllllll}
\hline & \multicolumn{6}{c}{ Curry intake frequency in a month } & \\
\cline { 2 - 6 } Variables & \multicolumn{2}{c}{$\begin{array}{c}\text { No } \\
(n=747) \mathrm{SE}\end{array}$} & $\begin{array}{c}1 \\
(n=347) \mathrm{SE}\end{array}$ & $\begin{array}{c}\geq 2 \\
(n=256) \mathrm{SE}\end{array}$ & \\
\hline Blood $\mathrm{Pb}$ concentrations $(\mu \mathrm{g} / \mathrm{dL})$ & 2.09 & $0.045^{\mathrm{a}}$ & 2.05 & 0.059 & 1.86 & 0.061 & $0.006^{* *, \mathrm{~b}}$ \\
Blood $\mathrm{Hg}$ concentrations $(\mu \mathrm{g} / \mathrm{L})$ & 4.05 & 0.125 & 3.80 & 0.143 & 3.49 & 0.215 & $0.040^{*}$ \\
Blood Cd concentrations $(\mu \mathrm{g} / \mathrm{L})$ & 1.07 & 0.032 & 0.89 & 0.029 & 0.81 & 0.032 & $<0.001^{* * *}$ \\
\hline
\end{tabular}

${ }^{a}$ Results are expressed as means \pm SEs.

${ }^{\mathrm{b}} \mathrm{Blood} \mathrm{Pb}, \mathrm{Hg}$, and $\mathrm{Cd}$ concentrations were treated as continuous variables.

$P$ values were calculated using a generalized linear model for continuous variables.

${ }^{*} P<0.05,{ }^{* *} P<0.01,{ }^{* * *} P<0.001$.

Table 4. Sex, lifetime smoking history, curry intake, and heavy metal blood concentrations.

\begin{tabular}{|c|c|c|c|c|c|c|}
\hline \multirow[b]{2}{*}{ Variables } & \multicolumn{6}{|c|}{ Blood heavy metal concentration $(n=1350)$} \\
\hline & \multicolumn{2}{|c|}{$\mathrm{Pb}(\mu \mathrm{g} / \mathrm{dL}) \mathrm{SE}\left(\mathrm{P}^{\mathrm{a}}\right)$} & \multicolumn{2}{|c|}{$\operatorname{Hg}(\mu \mathrm{g} / \mathrm{L}) \mathrm{SE} \quad\left(\mathrm{P}^{\mathrm{a}}\right)$} & \multicolumn{2}{|c|}{$\mathrm{Cd}(\mu \mathrm{g} / \mathrm{L}) \mathrm{SE}\left(\mathrm{P}^{\mathrm{a}}\right)$} \\
\hline Sex & \multicolumn{2}{|c|}{$(<0.001)^{\text {*** }}$} & \multicolumn{2}{|c|}{$(<0.001)^{* * *}$} & \multicolumn{2}{|c|}{$(<0.001)^{* * *}$} \\
\hline Male $(n=610)$ & 2.32 & $0.052^{\mathrm{b}}$ & 4.59 & 0.162 & 0.87 & 0.034 \\
\hline Female $(n=740)$ & 1.77 & 0.032 & 3.22 & 0.091 & 1.08 & 0.024 \\
\hline Male & \multicolumn{2}{|c|}{$(0.037)^{*}$} & \multicolumn{2}{|c|}{$(0.202)$} & \multicolumn{2}{|c|}{$(<0.001)^{* * *}$} \\
\hline Curry intake $(n=272)$ & 2.22 & 0.068 & 4.41 & 0.214 & 0.74 & 0.029 \\
\hline Non curry intake $(n=338)$ & 2.41 & 0.069 & 4.74 & 0.201 & 0.97 & 0.056 \\
\hline Female & \multicolumn{2}{|c|}{$(0.095)$} & \multicolumn{2}{|c|}{$(0.002)^{* *}$} & \multicolumn{2}{|c|}{$(0.001)^{* *}$} \\
\hline Curry intake $(n=331)$ & 1.71 & 0.046 & 2.92 & 0.111 & 0.98 & 0.034 \\
\hline Non curry intake $(n=409)$ & 1.81 & 0.040 & 3.43 & 0.130 & 1.15 & 0.035 \\
\hline Lifetime smoking & \multicolumn{2}{|c|}{$(<0.001)^{* * *}$} & \multicolumn{2}{|c|}{$(<0.001)^{* * *}$} & \multicolumn{2}{|c|}{$(0.071)$} \\
\hline Smokers $(n=531)$ & 2.33 & 0.052 & 4.63 & 0.168 & 1.02 & 0.039 \\
\hline Non-smokers $(n=819)$ & 1.84 & 0.034 & 3.37 & 0.101 & 0.94 & 0.022 \\
\hline Smoker & \multicolumn{2}{|c|}{$(0.504)$} & \multicolumn{2}{|c|}{$(0.739)$} & \multicolumn{2}{|c|}{$(0.003)^{* *}$} \\
\hline Curry intake $(n=218)$ & 2.29 & 0.082 & 4.58 & 0.218 & 0.91 & 0.031 \\
\hline Non curry intake $(n=313)$ & 2.35 & 0.064 & 4.66 & 0.208 & 1.10 & 0.060 \\
\hline Non-smoker & \multicolumn{2}{|c|}{$(0.057)$} & \multicolumn{2}{|c|}{$(0.014)^{*}$} & \multicolumn{2}{|c|}{$(<0.001)^{* * *}$} \\
\hline Curry intake $(n=385)$ & 1.77 & 0.048 & 3.11 & 0.142 & 0.83 & 0.029 \\
\hline Non curry intake $(n=434)$ & 1.90 & 0.047 & 3.59 & 0.138 & 1.04 & 0.031 \\
\hline
\end{tabular}

${ }^{a} P$ values were determined using the Chi-square test for categorial variables and a generalized linear model for continuous variables.

${ }^{\mathrm{b}}$ Results are expressed as means \pm SEs. ${ }^{*} P<0.05,{ }^{* *} P<0.01,{ }^{* * *} P<0.001$.

vs. $1.86 \pm 0.061, P=0.006 ; \mathrm{Hg}(\mu \mathrm{g} / \mathrm{L}), 4.05 \pm 0.125$ vs. $3.80 \pm 0.143$ vs. $3.49 \pm 0.061, P=0.040 ; \mathrm{Cd}(\mu \mathrm{g} / \mathrm{L}), 1.07 \pm$ 0.032 vs. $0.89 \pm 0.029$ vs. $0.81 \pm 0.032, P<0.001$.).

\section{Relations between sex, smoking, and curry intake and heavy} metal blood concentrations

Relationships between blood concentrations of heavy metals and sex, lifetime smoking, and curry intake are pre- sented in Table 4. Statistically significant differences were observed between mean heavy metal concentrations in males and females. $\mathrm{Pb}$ and $\mathrm{Hg}$ concentrations were significantly higher in males whereas $\mathrm{Cd}$ concentration was significantly higher in females. For males, mean $\mathrm{Pb}$ and $\mathrm{Cd}$ concentrations were significantly lower in the curry intake group than in the non-curry intake group (curry intake group vs. non-curry intake group: $\mathrm{Pb}(\mu \mathrm{g} / \mathrm{dL}), 2.22 \pm 0.068$ 
vs. $2.41 \pm 0.069, P=0.037 ; \mathrm{Cd}(\mu \mathrm{g} / \mathrm{L}): 0.74 \pm 0.029$ vs. $0.97 \pm 0.056, P<0.001$ ), and for females, mean $\mathrm{Hg}$ and $\mathrm{Cd}$ concentrations were significantly lower in the curry intake group (curry intake group vs. non-curry intake group: $\mathrm{Hg}$ $(\mu \mathrm{g} / \mathrm{dL}), 2.92 \pm 0.111$ vs. $3.43 \pm 0.130, P=0.002 ; \mathrm{Cd}(\mu \mathrm{g} /$ L), $0.98 \pm 0.034$ vs. $1.15 \pm 0.035, P=0.001)$. In both sexes, Cd concentrations were lower in those that consumed curry $>$ once per month.

For this analysis, subjects were classified as lifetime smokers (current smokers and ex-smokers) and non-smokers (never smoked). $\mathrm{Pb}$ and $\mathrm{Hg}$ concentrations were significantly higher in lifetime smokers than in non-smokers (both $P<0.001)$. However, when curry intake was taken into consideration, different results were obtained. Mean $\mathrm{Cd}$ concentration was significantly lower in lifetime smokers that consumed curry than in those that $\operatorname{did}$ not $(P=0.003)$, and in non-smokers, those that consumed curry had significantly lower $\mathrm{Hg}$ and $\mathrm{Cd}$ concentrations than those that did not $(P=0.014$ and $P<0.001$, respectively). These findings suggest regular curry consumption reduced $\mathrm{Cd}$ concentrations in lifetime smokers and non-smokers.

\section{Blood heavy metal concentrations in the no-HTN, pre-HTN and HTN groups}

Of 1,350 subjects, 798 (59.1\%) were not hypertensive, $313(23.2 \%)$ were pre-hypertensive, and $239(17.7 \%)$ were hypertensive. Relations between the prevalence of HTN and heavy metal blood concentrations are summarized in Table 5. The prevalence of HTN was found to depend on sex, age, BMI, residence, educational level, smoking status, diabetes, and heavy metal blood concentrations (all $P<$ $0.001)$. The prevalence of HTN in males $(21.6 \%)$ was significantly higher than in females $(14.6 \%, P<0.001)$. The prevalence of HTN was lowest (4.3\%) in the 20 s group, and increased to $6.9 \%, 15.7 \%$, and $33.6 \%$ in the $30 \mathrm{~s}, 40 \mathrm{~s}$, and 50 s, respectively, and was highest $(42.4 \%)$ in the 60 s group. The prevalence of HTN (24.3\%) in rural residents was significantly higher than in urban residents $(16.9 \%, P=0.001)$, and in those with less than a college education $(25.5 \%)$ than in those educated to college level or more $(10.6 \%, P<$ 0.001). HTN was more prevalent in lifetime smokers $(21.3 \%, P<0.001)$ than in non-smokers $(15.8 \%, P<0.001)$, and in those with diabetes mellitus, the prevalence rate of HTN was $43.6 \%$, which was 2.7 times higher than in people without diabetes $(16.1 \%, P<0.001)$. Blood concentrations of $\mathrm{Pb}, \mathrm{Hg}$, and $\mathrm{Cd}$ were also significantly higher in those with HTN than those with a normal HTN status (all $P<$ $0.001)$.

\section{Effect of curry intake on relationships between blood heavy metal concentrations and the prevalence of hypertension}

Table 6 shows the relationship between blood heavy metal concentration and the probability of HTN. For this analysis, subjects with a pre-HTN status were assigned with those without HTN to a normal HTN group. Those that consumed curry regularly had a lower prevalence of HTN
(OR: 1.503) than those that did not (OR: 1.862). After adjusting for sex, age, BMI, smoking, and the prevalence of HTN (OR) was reduced in both curry intake and non-curry intake groups. In Model 1, sex and age were adjusted. In Model 2, sex, age, BMI, and smoking were adjusted and the probability of HTN in non-curry intake group was increased by 1.40 fold for a $1-\mu \mathrm{g} / \mathrm{dL}$ increase in $\mathrm{Pb}$ concentration, 1.08 fold for a $1-\mu \mathrm{g} / \mathrm{L}$ increase in $\mathrm{Hg}$ concentration, and 1.49 fold for a $1-\mu \mathrm{g} / \mathrm{L}$ increase in $\mathrm{Cd}$ concentration. However, in the curry intake group, no significant relation was found between heavy metal blood concentrations and prevalence of HTN in Model 1 or Model 2.

\section{Discussion}

Curcumin, which is a major component of curry, has both chelating and antioxidant effects, and can reduce heavy metal levels in vivo. Curcumin has been reported to rescue cells from $\mathrm{Cd}$-induced toxicity by attenuating lipid peroxidation, depleting glutathione, and modulating levels of oxidative stress related enzymes, and by chelating $\mathrm{Cd}$ (Mohajeri et al. 2017). The keto-enol tautomerization exhibited by the $\beta$-diketone moiety of curcumin has shown to have free radical scavenging effects and act as an antioxidant, and can also chelate positively charged metal ions (Ferrari et al. 2014). In addition to its antioxidant effects, curcumin also possesses anti-inflammatory and anti-tumor effects and has been suggested to help prevent Alzheimer's disease and other neurodegenerative diseases (Yanagisawa et al. 2010).

Heavy metals like $\mathrm{Pb}, \mathrm{Hg}$, and $\mathrm{Cd}$ are toxic to the human body, and can cause various diseases, such as, CVD and neurodegenerative diseases like Alzheimer's disease and Parkinson's disease (Gupta et al. 2015; Kukongviriyapan et al. 2016). Heavy metals can increase ROS and reactive nitrogen species levels, and thus, increase oxidative stress (Jomova and Valko 2011), which can cause DNA damage and oxidize protein thiol groups. A correlation between CVD and Cd exposure has also been reported (Baek and Chung 2017). Heavy metals are excreted from proximal kidney tubules, and $\mathrm{Cd}$ exposure has been linked with chronic kidney disease (Byber et al. 2016; Satarug et al. 2017b). For this reason, individuals with an eGFR of $<60$ $\mathrm{mL} / \mathrm{min} / 1.73 \mathrm{~m}^{2}(n=8)$ were exclude from this study to enable us to determine the effect of curry intake on heavy metal-induced HTN.

Chelation therapy has been traditionally used to treat heavy metal toxicity. A chelating agent is any compound that can bind to a metal ion to form a ring-like complex called a chelate (Flora and Pachauri 2010). Chelation can reduce heavy metal burden in the body, and chelating agents, such as, desferrioxamine B for Fe overload and ethylenediaminetetraacetic acid (EDTA) or meso-2,3-dimercaptosuccinic acid (DMSA) for Hg toxicity, respectively (Ferrero 2016). Furthermore, chelation therapy is used offlabel to treat CVD (Sultan et al. 2017). However, chelation therapies have side effects because they also chelate other 
Table 5. Demographic characteristics, heavy metal blood concentrations, and HTN statuses.

\begin{tabular}{|c|c|c|c|c|c|c|c|}
\hline \multirow{3}{*}{ Variables } & \multicolumn{6}{|c|}{ Hypertension prevalence ( $\geq 19$ years) } & \multirow{3}{*}{$P$ value } \\
\hline & \multicolumn{2}{|c|}{ No-Hypertension } & \multicolumn{2}{|c|}{ Pre-Hypertension } & \multicolumn{2}{|c|}{ Hypertension } & \\
\hline & $(n=7$ & 98) SE & $(n=$ & 313) SE & $(n=239)$ & ) $\mathrm{SE}$ & \\
\hline Sex & & & & & & & $<0.001^{* * *, a}$ \\
\hline Male & $48.1 \%^{\mathrm{c}}$ & & $30.3 \%$ & & $21.6 \%$ & & \\
\hline Female & $67.9 \%$ & & $17.5 \%$ & & $14.6 \%$ & & \\
\hline Age (Years) & & & & & & & $<0.001^{* * *}$ \\
\hline $19-29$ & $78.1 \%$ & & $17.5 \%$ & & $4.3 \%$ & & \\
\hline $30-39$ & $71.7 \%$ & & $21.5 \%$ & & $6.9 \%$ & & \\
\hline $40-49$ & $55.2 \%$ & & $29.2 \%$ & & $15.7 \%$ & & \\
\hline $50-59$ & $39.8 \%$ & & $26.6 \%$ & & $33.6 \%$ & & \\
\hline $60-64$ & $34.1 \%$ & & $23.5 \%$ & & $42.4 \%$ & & \\
\hline $\operatorname{BMI}\left(\mathrm{kg} / \mathrm{m}^{2}\right)^{\mathrm{d}}$ & 22.68 & 0.126 & 24.59 & 0.219 & 25.70 & 0.293 & $<0.001^{* * *, b}$ \\
\hline Residence $^{e}$ & & & & & & & $0.001^{* *}$ \\
\hline Urban resident & $60.7 \%$ & & $22.5 \%$ & & $16.9 \%$ & & \\
\hline Rural resident & $45.2 \%$ & & $30.5 \%$ & & $24.3 \%$ & & \\
\hline Educational level & & & & & & & $<0.001^{* * *}$ \\
\hline Over college & $66.8 \%$ & & $22.7 \%$ & & $10.6 \%$ & & \\
\hline Less than college & $49.7 \%$ & & $24.8 \%$ & & $25.5 \%$ & & \\
\hline Lifetime smoking $^{\mathrm{f}}$ & & & & & & & $<0.001^{* * *}$ \\
\hline Smokers & $50.4 \%$ & & $28.3 \%$ & & $21.3 \%$ & & \\
\hline Non-smokers & $63.6 \%$ & & $20.6 \%$ & & $15.8 \%$ & & \\
\hline Diabetes & & & & & & & $<0.001^{* * *}$ \\
\hline Yes & $30.6 \%$ & & $25.8 \%$ & & $43.6 \%$ & & \\
\hline No & $60.3 \%$ & & $23.6 \%$ & & $16.1 \%$ & & \\
\hline $\begin{array}{l}\text { Blood } \mathrm{Pb} \\
\text { concentration }(\mu \mathrm{g} / \mathrm{dL})^{\mathrm{d}}\end{array}$ & 1.87 & 0.038 & 2.15 & 0.061 & 2.44 & 0.080 & $<0.001^{* * *}$ \\
\hline $\begin{array}{l}\text { Blood Hg } \\
\text { concentration }(\mu \mathrm{g} / \mathrm{L})^{\mathrm{d}}\end{array}$ & 3.42 & 0.099 & 4.25 & 0.202 & 4.91 & 0.276 & $<0.001^{* * *}$ \\
\hline $\begin{array}{l}\text { Blood Cd } \\
\text { concentration }(\mu \mathrm{g} / \mathrm{L})^{\mathrm{d}}\end{array}$ & 0.88 & 0.021 & 1.01 & 0.042 & 1.24 & 0.071 & $<0.001^{* * *}$ \\
\hline
\end{tabular}

a $P$ values were determined using the Chi-square test.

${ }^{\mathrm{b}} P$ values were determined using a generalized linear model for continuous variables.

${ }^{\mathrm{c}}$ Categorical variables are expressed as percentages.

${ }^{d}$ Results of continuous variables are expressed as mean \pm SEs.

"Administrative districts of South Korea, "Dong (Neighborhood)" residents were classified as urban residents while "Eup (Town) or Myeon (Township) residents were classified as rural residents.

'Subjects who had never smoked were classified as "non-smokers" while those who had smoked in the past and current smokers were classified as "smokers".

${ }^{*} P<0.05,{ }^{* *} P<0.01,{ }^{* * *} P<0.001$.

essential ions like calcium or magnesium. In fact, one case report of the death of a boy with autism caused by a heart attack was attributed to EDTA treatment (Baxter and Krenzelok 2008). Therefore, methods for reducing the side effects of chelation therapy have been studied based on the use of natural products or foods (Gupta et al. 2015), essential metals, vitamins, phytochemicals, or probiotics (Zhai et al. 2015). Representative phytochemical antidotes for heavy metal induced toxicity include allicin from garlic (Aslani et al. 2010; Shahsavani et al. 2011), anthocyanin from cherry, grapes and berries ( $\mathrm{Li}$ et al. 2017), catechins from tea, cocoa, peach, and berries (Chen et al. 2016). Furthermore, many reports have been issued on the effect of curry consumption on heavy metal induced toxicity. 
Table 6. Unadjusted and adjusted ORs for the prevalence of HTN for different heavy metal blood concentrations and curry intake status.

\begin{tabular}{|c|c|c|c|c|c|c|c|c|}
\hline \multirow{2}{*}{$\mathrm{Pb}$} & \multicolumn{4}{|c|}{ Curry intake $(n=603)$} & \multicolumn{4}{|c|}{ Non-Curry intake $(n=747)$} \\
\hline & $\mathrm{B}$ & $95 \% \mathrm{CI}^{\mathrm{b}}$ & $\mathrm{OR}^{\mathrm{c}}$ & $P$ value $^{\mathrm{a}}$ & $\mathrm{B}$ & $95 \% \mathrm{CI}^{\mathrm{b}}$ & $\mathrm{OR}^{\mathrm{c}}$ & $P$ value $^{\mathrm{a}}$ \\
\hline Unadjusted & 0.408 & $0.137-0.679$ & 1.503 & $0.003^{* *}$ & 0.622 & $0.326-0.918$ & 1.862 & $<0.001^{* * *}$ \\
\hline Model 1 & 0.069 & $-0.225-0.363$ & 1.072 & 0.643 & 0.352 & $0.083-0.621$ & 1.421 & $0.011^{*}$ \\
\hline Model 2 & 0.103 & $-0.199-0.405$ & 1.108 & 0.502 & 0.336 & $0.054-0.617$ & 1.399 & $0.020^{*}$ \\
\hline \multirow{2}{*}{$\mathrm{Hg}$} & \multicolumn{4}{|c|}{ Curry intake } & \multicolumn{4}{|c|}{ Non-Curry intake } \\
\hline & B & $95 \% \mathrm{CI}^{\mathrm{b}}$ & $\mathrm{OR}^{\mathrm{c}}$ & $P$ value $^{\mathrm{a}}$ & $\mathrm{B}$ & $95 \% \mathrm{CI}^{\mathrm{b}}$ & $\mathrm{OR}^{\mathrm{c}}$ & $P$ value $^{\mathrm{a}}$ \\
\hline Unadjusted & 0.106 & $0.028-0.184$ & 1.112 & $0.008^{* *}$ & 0.138 & $0.078-0.199$ & 1.149 & $<0.001^{* * *}$ \\
\hline Model 1 & 0.004 & $-0.135-0.143$ & 1.004 & 0.952 & 0.087 & $0.020-0.153$ & 1.090 & $0.011^{*}$ \\
\hline Model 2 & -0.032 & $-0.196-0.133$ & 0.969 & 0.704 & 0.074 & $0.007-0.141$ & 1.077 & $0.030^{*}$ \\
\hline \multirow{2}{*}{$\mathrm{Cd}$} & \multicolumn{4}{|c|}{ Curry intake } & \multicolumn{4}{|c|}{ Non-Curry intake } \\
\hline & B & $95 \% \mathrm{CI}^{\mathrm{b}}$ & $\mathrm{OR}^{\mathrm{c}}$ & $P$ value ${ }^{\mathrm{a}}$ & B & $95 \% \mathrm{CI}^{\mathrm{b}}$ & $\mathrm{OR}^{\mathrm{c}}$ & $P$ value $^{\mathrm{a}}$ \\
\hline Unadjusted & 0.516 & $0.071-0.962$ & 1.676 & $0.023^{*}$ & 0.687 & $0.410-0.964$ & 1.988 & $<0.001^{* * *}$ \\
\hline Model 1 & 0.043 & $-0.530-0.615$ & 1.044 & 0.883 & 0.375 & $0.042-0.709$ & 1.455 & $0.028^{*}$ \\
\hline Model 2 & -0.060 & $-0.648-0.528$ & 0.942 & 0.841 & 0.401 & $0.057-0.745$ & 1.494 & $0.022^{*}$ \\
\hline
\end{tabular}

${ }^{\text {a }} P$ values were determined by logistic regression analysis.

${ }^{\mathrm{b}} \mathrm{CI}$, confidence interval.

'Odds ratio (OR) can be abbreviated as $\mathrm{e}^{\mathrm{B}}$, $\operatorname{Exp}(\mathrm{B})$ (on SPSS output), or exp(B).

$\mathrm{B}$ represents the slope of logistic regression, where a positive slope means positive

relationship $(\mathrm{OR}>1)$. Negative slope means negative relationship $(\mathrm{OR}<1)$.

Model 1 : Adjusted for sex and age.

Model 2 : Adjusted for sex, age, smoking, and BMI.

${ }^{*} P<0.05,{ }^{* *} P<0.01,{ }^{* * *} P<0.001$.

Interestingly, aqueous curry leaf has been reported to protect against Cd-induced oxidative stress (Mitra et al. 2012).

In the present study, we sought to identify the beneficial effects of curry on blood heavy metal concentrations and on prevalence of HTN by using KNHANES data, and analyzed data by classifying the study subjects by frequency of curry intake (none, once in a month, twice or more a month). We found that heavy metal concentrations decreased significantly with increasing curry intake (Table $3)$.

No significant difference was found between males and females in terms of the percentage that ate curry at least once per month $(54.2 \%$ in males vs. $57.6 \%$ in females, $P=$ 0.283). $\mathrm{Pb}$ and $\mathrm{Hg}$ concentrations were lower in females than in males, whereas $\mathrm{Cd}$ concentration was higher in females (Table 4). $\mathrm{Fe}$ and $\mathrm{Cd}$ compete for absorption and transportation in the body (Montalbetti et al. 2014), because they use the same transporter (divalent metal transporter 1(DMIT1)), and thus, reduction in Fe can increase Cd concentrations, and females of reproductive age and children are susceptible to Cd exposure (Suh et al. 2016). In males, $\mathrm{Pb}$ and $\mathrm{Cd}$ concentrations were significantly lower those that consumed curry more than once a month during the previous year $(P=0.037,<0.001$, respectively), whereas in females, $\mathrm{Hg}$ and $\mathrm{Cd}$ concentrations were significantly lower $(P=0.002,0.001$, respectively).

A significant difference in curry intake was observed between age groups $(P<0.001)$, curry intakes were higher in younger age groups. In the 20 s group, the proportion that consumed curry at least once a month was about $50 \%$, whereas, in those aged over 60 , it was $24 \%$. The mean concentration of heavy metals in blood in subjects in their 20s was $0.6 \pm 0.40 \mu \mathrm{g} / \mathrm{L}$, and this was more than twice as high $(1.37 \pm 0.70 \mu \mathrm{g} / \mathrm{L})$ in those aged $\geq 60$. Considering the relationship found in the present study between curry consumption and heavy metal concentrations in blood, it might be beneficial to recommend routine curry meals, especially for the elderly.

We found no difference between the heavy metal blood concentrations of urban and rural residents $(P=0.21)$, but 
found significant differences between the heavy metal concentrations of residents in different cities. The highest mean $\mathrm{Hg}$ concentration was found in inhabitants of Jeju island, the largest island in Korea, which we suggest was probably caused by higher seafood intake (Camur et al. 2016).

Smoking was found to affect heavy metal blood concentrations. In the lifetime smokers group, curry consumption was associated with lower $\mathrm{Cd}$ concentration $(P=0.003$, Table 4), and in lifetime non-smokers, curry consumption was associated with lower $\mathrm{Hg}$ and $\mathrm{Cd}$ concentrations $(P=$ 0.014 and $P<0.001$, respectively). These findings indicate that in smokers, curry consumption could reduce Cd concentration. Furthermore, we suggest that the effect of curry consumption on blood Cd levels attributable to secondhand smoke be investigated (Jung et al. 2015).

We focused on the effect of curry on HTN and analyzed data from the KNHANES 2013. The most interesting finding of the present study was that those who consumed curry more than once a month showed lower heavy metal concentrations (Table 3) with reduced risk of HTN than those in the curry non-intake group (Table 6). The curry intake group had a lower odd ratios for the prevalence of HTN than the non-curry intake group. After adjusting for sex, age, smoking, and BMI, statistically significant differences were only obtained for the non-curry intake group. Probably, other factors influenced relations in the curry intake group.

The present study has several limitations that warrant mention. First, we divided subjects into two groups based on curry intake. Second, blood concentrations of heavy metals reflected only one moment in time and HTN is a progressive process. Third, we were not able to further stratification in the curry intake group, because detailed information was unavailable. Thus, we suggest further more detailed studies be conducted aimed at better understanding the protective effects of curry consumption. Forth, it was difficult to investigate the causal relationship between curry intake and heavy metal concentrations in blood or HTN because of the cross-sectional nature of the study. Fifth, we were unable to control for epigenetic factors. Sixth, all those that participated in KNHANES were relatively healthy because individuals in hospitals or residing in nursing homes were excluded. Finally, the 24-h recall method might not have accurately represented curry intake.

In Korea, curry is mainly used in the form of curry powder. In general, the most common curry powder in the market is around $10 \%$ of total $20 \mathrm{~g}$ portion per person. It means about $2 \mathrm{~g}$ of Curcuma longa is included in it and has 1-11.5 mg of curcumin present. Our study shows that taking curry once a month as a meal can protect against heavy metal burden in the body.

It is hoped the results of the present study will improve Korean eating habits. Currently, the prevalence of chronic diseases like HTN is increasing in Korea due to dietary changes toward a Western diet, and increasing curry con- sumption at home meals offers a possible means of reducing heavy metal accumulation, especially in the elderly. Therefore, we suggest prospective studies be conducted to determine the effects of curry intake on heavy metal blood concentrations and on the prevalence of HTN, because such research would undoubtedly provide valuable information on the health benefits of eating curry.

\section{Acknowledgments}

This work was supported by OTTOGI Foundation (No. 2013-023) and Sunchon Research Center for Natural Medicines (2013-2014). Authors' contributions are as follows: J. W. C., S. J., and M-S. K. designed and conducted the study; J. W. C. and S. J. collected data and performed the statistical analyses; C. O. and M-S. K. interpreted data; J. W. C., S-Y. S., and M-S. K. drafted the paper.

\section{Conflict of Interest}

The authors declare no conflict of interest.

\section{References}

An, H.C., Sung, J.H., Lee, J., Sim, C.S., Kim, S.H. \& Kim, Y. (2017) The association between cadmium and lead exposure and blood pressure among workers of a smelting industry: a cross-sectional study. Ann. Occup. Environ. Med., 29, 47.

Angeli, J.K., Cruz Pereira, C.A., de Oliveira Faria, T., Stefanon, I., Padilha, A.S. \& Vassallo, D.V. (2013) Cadmium exposure induces vascular injury due to endothelial oxidative stress: the role of local angiotensin II and COX-2. Free Radic. Biol. Med., 65, 838-848.

Arbi, S., Oberholzer, H.M., Van Rooy, M.J., Venter, C. \& Bester, M.J. (2017) Effects of chronic exposure to mercury and cadmium alone and in combination on the coagulation system of Sprague-Dawley rats. Ultrastruct. Pathol., 41, 275-283.

Aslani, M.R., Najarnezhad, V. \& Mohri, M. (2010) Individual and combined effect of meso-2,3-dimercaptosuccinic acid and allicin on blood and tissue lead content in mice. Planta Med., 76, 241-244.

Astrup, A., Dyerberg, J., Selleck, M. \& Stender, S. (2008) Nutrition transition and its relationship to the development of obesity and related chronic diseases. Obes. Rev., 9 Suppl 1, 48-52.

Baek, K. \& Chung, I. (2017) Cadmium exposure is associated with monocyte count and monocyte to HDL ratio, a marker of inflammation and future cardiovascular disease in the male population. J. Korean Med. Sci., 32, 1415-1422.

Baxter, A.J. \& Krenzelok, E.P. (2008) Pediatric fatality secondary to EDTA chelation. Clin. Toxicol. (Phila), 46, 1083-1084.

Byber, K., Lison, D., Verougstraete, V., Dressel, H. \& Hotz, P. (2016) Cadmium or cadmium compounds and chronic kidney disease in workers and the general population: a systematic review. Crit. Rev. Toxicol., 46, 191-240.

Camur, D., Guler, C., Vaizoglu, S.A. \& Ozdilek, B. (2016) Determining mercury levels in anchovy and in individuals with different fish consumption habits, together with their neurological effects. Toxicol. Ind. Health, 32, 1215-1223.

Cao, H., Yu, H., Feng, Y., Chen, L. \& Liang, F. (2017) Curcumin inhibits prostate cancer by targeting PGK1 in the FOXD3/ miR-143 axis. Cancer Chemother. Pharmacol., 79, 985-994.

Chen, J., Du, L., Li, J. \& Song, H. (2016) Epigallocatechin-3-gallate attenuates cadmium-induced chronic renal injury and fibrosis. Food Chem. Toxicol., 96, 70-78.

Dai, J.B., Wang, Z.X. \& Qiao, Z.D. (2015) The hazardous effects of tobacco smoking on male fertility. Asian J. Androl., 17, 954-960. 
Ferrari, E., Benassi, R., Sacchi, S., Pignedoli, F., Asti, M. \& Saladini, M. (2014) Curcumin derivatives as metal-chelating agents with potential multifunctional activity for pharmaceutical applications. J. Inorg. Biochem., 139, 38-48.

Ferrero, M.E. (2016) Rationale for the successful management of EDTA chelation therapy in human burden by toxic metals. Biomed. Res. Int., 2016, 8274504.

Flora, S.J. \& Pachauri, V. (2010) Chelation in metal intoxication. Int. J. Environ. Res. Public Health, 7, 2745-2788.

Go, Y.M., Sutliff, R.L., Chandler, J.D., Khalidur, R., Kang, B.Y., Anania, F.A., Orr, M., Hao, L., Fowler, B.A. \& Jones, D.P. (2015) Low-dose cadmium causes metabolic and genetic dysregulation associated with fatty liver disease in mice. Toxicol. Sci., 147, 524-534.

Gupta, V.K., Singh, S., Agrawal, A., Siddiqi, N.J. \& Sharma, B. (2015) Phytochemicals mediated remediation of neurotoxicity induced by heavy metals. Biochem. Res. Int., 2015, 534769 .

Jomova, K. \& Valko, M. (2011) Advances in metal-induced oxidative stress and human disease. Toxicology, 283, 65-87.

Jung, S.Y., Kim, S., Lee, K., Kim, J.Y., Bae, W.K., Lee, K., Han, J.S. \& Kim, S. (2015) Association between secondhand smoke exposure and blood lead and cadmium concentration in community dwelling women: the fifth Korea National Health and Nutrition Examination Survey (2010-2012). BMJ Open, 5, e008218-2015-008218.

Korea Centers for Disease Control and Prevention (KCDC) (2013) KNHANES Clinical Laboratory Test for the Sixth Korea National Health and Nutrition Examination Survey (KNHANES). Osong, Cheonju, Korea: Korea Centers for Disease Control and Prevention, Neodin Medical Institute, Seoul, Korea.

Kim, N.H., Hyun, Y.Y., Lee, K.B., Chang, Y., Ryu, S., Oh, K.H. \& Ahn, C. (2015) Environmental heavy metal exposure and chronic kidney disease in the general population. J. Korean Med. Sci., 30, 272-277.

Kim, N.S., Ahn, J., Lee, B.K., Park, J. \& Kim, Y. (2017) Environmental exposures to lead, mercury, and cadmium among South Korean teenagers (KNHANES 2010-2013): Body burden and risk factors. Environ. Res., 156, 468-476.

Kim, Y. \& Lee, B.K. (2012) Associations of blood lead, cadmium, and mercury with estimated glomerular filtration rate in the Korean general population: analysis of 2008-2010 Korean National Health and Nutrition Examination Survey data. Environ. Res., 118, 124-129.

Kim, Y.O. (2009) Dietary patterns associated with hypertension among Korean males. Nutr. Res. Pract., 3, 162-166.

Kukongviriyapan, U., Apaijit, K. \& Kukongviriyapan, V. (2016) Oxidative stress and cardiovascular dysfunction associated with cadmium exposure: beneficial effects of curcumin and tetrahydrocurcumin. Tohoku J. Exp. Med., 239, 25-38.

Kuriakose, M.A., Ramdas, K., Dey, B., Iyer, S., Rajan, G., Elango, K.K., Suresh, A., Ravindran, D., Kumar, R.R., R, P., Ramachandran, S., Kumar, N.A., Thomas, G., Somanathan, T., Ravindran, H.K., et al. (2016) A randomized double-blind placebo-controlled phase IIB trial of curcumin in oral leukoplakia. Cancer. Prev. Res. (Phila), 9, 683-691.

Kwon, Y. (2014) Estimation of curcumin intake in Korea based on the Korea National Health and Nutrition Examination Survey (2008-2012). Nutr. Res. Pract., 8, 589-594.

Lee, B.K. \& Kim, Y. (2014) Sex-specific profiles of blood metal levels associated with metal-iron interactions. Saf. Health Work, 5, 113-117.

Li, X., Jiang, X., Sun, J., Zhu, C., Li, X., Tian, L., Liu, L. \& Bai, W. (2017) Cytoprotective effects of dietary flavonoids against cadmium-induced toxicity. Ann. NY Acad. Sci., 1398, 5-19.

Lincoln, R.A., Shine, J.P., Chesney, E.J., Vorhees, D.J., Grandjean, P. \& Senn, D.B. (2011) Fish consumption and mercury exposure among Louisiana recreational anglers. Environ. Health Perspect., 119, 245-251.
Liu, M.Y., Li, N., Li, W.A. \& Khan, H. (2017) Association between psychosocial stress and hypertension: a systematic review and meta-analysis. Neurol. Res., 39, 573-580.

Mahammedi, H., Planchat, E., Pouget, M., Durando, X., Cure, H., Guy, L., Van-Praagh, I., Savareux, L., Atger, M., BayetRobert, M., Gadea, E., Abrial, C., Thivat, E., Chollet, P. \& Eymard, J.C. (2016) The new combination docetaxel, prednisone and curcumin in patients with castration-resistant prostate cancer: a pilot phase II study. Oncology, 90, 69-78.

Mitra, E., Ghosh, A.K., Ghosh, D., Mukherjee, D., Chattopadhyay, A., Dutta, S., Pattari, S.K. \& Bandyopadhyay, D. (2012) Protective effect of aqueous Curry leaf (Murraya koenigii) extract against cadmium-induced oxidative stress in rat heart. Food Chem. Toxicol., 50, 1340-1353.

Mohajeri, M., Rezaee, M. \& Sahebkar, A. (2017) Cadmiuminduced toxicity is rescued by curcumin: a review. Biofactors, 43, 645-661.

Montalbetti, N., Simonin, A., Dalghi, M.G., Kovacs, G. \& Hediger, M.A. (2014) Development and validation of a fast and homogeneous cell-based fluorescence screening assay for divalent metal transporter 1 (DMT1/SLC11A2) using the FLIPR tetra. J. Biomol. Screen., 19, 900-908.

Nascimento, C.R.B., Risso, W.E. \& Martinez, C.B.D.R. (2016) Lead accumulation and metallothionein content in female rats of different ages and generations after daily intake of $\mathrm{Pb}$-contaminated food. Environ. Toxicol. Pharmacol., 48, 272-277.

Pal, M., Sachdeva, M., Gupta, N., Mishra, P., Yadav, M. \& Tiwari, A. (2015) Lead exposure in different organs of mammals and prevention by curcumin-nanocurcumin: a review. Biol. Trace Elem. Res., 168, 380-391.

Rodriguez-Iturbe, B., Pons, H. \& Johnson, R.J. (2017) Role of the immune system in hypertension. Physiol. Rev., 97, 1127-1164.

Satarug, S., Vesey, D.A. \& Gobe, G.C. (2017a) Current health risk assessment practice for dietary cadmium: Data from different countries. Food Chem. Toxicol., 106, 430-445.

Satarug, S., Vesey, D.A. \& Gobe, G.C. (2017b) Kidney cadmium toxicity, diabetes and high blood pressure: the perfect storm. Tohoku J. Exp. Med., 241, 65-87.

Schwandt, A., Denkinger, M., Fasching, P., Pfeifer, M., Wagner, C., Weiland, J., Zeyfang, A. \& Holl, R.W. (2017) Comparison of MDRD, CKD-EPI, and Cockcroft-Gault equation in relation to measured glomerular filtration rate among a large cohort with diabetes. J. Diabetes Complications, 31, 1376-1383.

Shahsavani, D., Baghshani, H. \& Alishahi, E. (2011) Efficacy of allicin in decreasing lead $(\mathrm{Pb})$ accumulation in selected tissues of lead-exposed common carp (Cyprinus carpio). Biol. Trace Elem. Res., 142, 572-580.

Shin, J.Y., Kim, J.M. \& Kim, Y. (2013) Associations between dietary patterns and hypertension among Korean adults: the Korean National Health and Nutrition Examination Survey (2008-2010). Nutr. Res. Pract., 7, 224-232.

Simoes, M.R., Preti, S.C., Azevedo, B.F., Fiorim, J., Freire, D.D. Jr., Covre, E.P., Vassallo, D.V. \& Dos Santos, L. (2017) Lowlevel chronic lead exposure impairs neural control of blood pressure and heart rate in rats. Cardiovasc. Toxicol., 17, 190-199.

Sinha, R., Anderson, D.E., McDonald, S.S. \& Greenwald, P. (2003) Cancer risk and diet in India. J. Postgrad. Med., 49, 222-228.

Suh, Y.J., Lee, J.E., Lee, D.H., Yi, H.G., Lee, M.H., Kim, C.S., Nah, J.W. \& Kim, S.K. (2016) Prevalence and relationships of iron deficiency anemia with blood cadmium and vitamin D levels in Korean women. J. Korean Med. Sci., 31, 25-32.

Sultan, S., Murarka, S., Jahangir, A., Mookadam, F., Tajik, A.J. \& Jahangir, A. (2017) Chelation therapy in cardiovascular disease: an update. Expert Rev. Clin. Pharmacol., 10, 843-854.

Sun, H., Wang, N., Nie, X., Zhao, L., Li, Q., Cang, Z., Chen, C., Lu, M., Cheng, J., Zhai, H., Xia, F., Ye, L. \& Lu, Y. (2017) 
Lead exposure induces weight gain in adult rats, accompanied by DNA hypermethylation. PLoS One, 12, e0169958.

Wallin, M., Barregard, L., Sallsten, G., Lundh, T., Karlsson, M.K., Lorentzon, M., Ohlsson, C. \& Mellstrom, D. (2016) Lowlevel cadmium exposure is associated with decreased bone mineral density and increased risk of incident fractures in elderly men: the MrOS Sweden study. J. Bone Miner. Res., 31, 732-741.

Wu, X., Chen, H., Huang, C., Gu, X., Wang, J., Xu, D., Yu, X., Shuai, C., Chen, L., Li, S., Xu, Y., Gao, T., Ye, M., Su, W., Liu, H., Zhang, J., Wang, C., Chen, J., Wang, Q. \& Cui, W. (2017) Curcumin attenuates surgery-induced cognitive dysfunction in aged mice. Metab. Brain Dis., 32, 789-798.

Yamamoto, C., Kaji, T., Sakamoto, M. \& Kozuka, H. (1993) Cadmium stimulation of plasminogen activator inhibitor-1 release from human vascular endothelial cells in culture. Toxicology, 83, 215-223.

Yanagisawa, D., Shirai, N., Amatsubo, T., Taguchi, H., Hirao, K., Urushitani, M., Morikawa, S., Inubushi, T., Kato, M., Kato, F., Morino, K., Kimura, H., Nakano, I., Yoshida, C., Okada, T., et al. (2010) Relationship between the tautomeric structures of curcumin derivatives and their $\mathrm{A} \beta$-binding activities in the context of therapies for Alzheimer's disease. Biomaterials, 31, 4179-4185.

Zhai, Q., Narbad, A. \& Chen, W. (2015) Dietary strategies for the treatment of cadmium and lead toxicity. Nutrients, 7, 552-571.

Zhou, S., Zhang, S., Shen, H., Chen, W., Xu, H., Chen, X., Sun, D., Zhong, S., Zhao, J. \& Tang, J. (2017) Curcumin inhibits cancer progression through regulating expression of microRNAs. Tumour Biol., 39, 1010428317691680. 